\title{
Escolas complementares na região fronteiriça do ex-Contestado (1928-1938)
}

\author{
Complementary schools in the border region of the \\ ex-Contestado (1928-1938)
}

Escuelas complementarias en la región fronteriza del

ex-Contestado (1928-1938)

MÁrCia Marlene StentZler (iDa

LIANE MARIA BERTUCCI D b

\begin{abstract}
Resumo
Neste artigo abordamos a criação e transformações das Escolas Complementares de Porto União (SC) e União da Vitória (PR), cidades fronteiriças criadas no final da Guerra do Contestado. Essas Escolas Complementares ofereceram, entre 1928 e 1938, oportunidades de estudos e de emprego praticamente imediato em uma área carente de professores e marcada pela convulsão, inclusive econômica, causada pelo conflito armado entre Paraná e Santa Catarina. 0 corpo docente e principalmente a conformação das duas instituições, a partir de determinações estaduais, resultou em peculiaridades que motivaram o trânsito de alunos que cruzaram a fronteira em busca de formação melhor e mais rápida. Em dezembro de 1938 a mudança na estrutura educacional em Santa Catarina extinguiu a formação de professores complementaristas; acontecimento que repercutiu não apenas do lado catarinense da fronteira, pois interrompeu o intercâmbio de uma década motivado pelas Escolas Complementares das duas cidades, escolas cujas atividades foram produtos e concorreram para a produção de "percepções do social" (CHARTIER, 1990).
\end{abstract}

Palavras-chave: Escolar complementar. Professor primário. Fronteira.

\section{Abstract}

In this article, we address the creation and transformations of the Complementary Schools in Porto União, Santa Catarina State and União da Vitória, in Paraná State, border towns that were created at the end of the Contestado War. From 1928 to 1938, these Complementary

\footnotetext{
a MMS: Universidade Estadual do Paraná (Unespar), União da Vitória, PR, Brasil. Doutora em Educação, e-mail: marcia.stentzler@unespar.edu.br

b LMB: Universidade Federal do Paraná (UFPR), Curitiba, PR, Brasil. Doutora em História, e-mail: lianebertucci@gmail.com
} 
Schools offered opportunities for study and almost immediate employment in an area lacking teachers and marked by turmoil, including economic upheaval, caused by the armed conflict between Paraná and Santa Catarina. The teaching staff, and especially the confirmation of the two institutions due to state determinations, resulted in peculiarities that motivated students to cross the border in search of better education and faster qualifications. In December of 1938, changes in the educational structure in Santa Catarina put an end to the qualification of complementarity teachers. This event that had repercussions not only in Santa Catarina, as it interrupted the exchange that had lasted a decade, motivated by the Complementary Schools of the two towns, schools whose activities were products and competed to produce "perceptions of the social" (CHARTIER, 1990).

Keywords: Complementary school. Primary school teacher. Border.

\section{Resumen}

En este artículo abordamos la creación y las transformaciones de las Escuelas Complementarias de Porto União (SC) y União da Vitória (PR), ciudades fronterizas creadas al final de la Guerra del Contestado. Estas Escuelas Complementarias ofrecieron entre 1928 y 1938 oportunidades de estudios y de empleo prácticamente inmediato en un área carente de profesores y marcada por la convulsión, incluso económica, causada por el conflicto armado entre Paraná y Santa Catarina. El cuerpo docente y principalmente la conformación de las dos instituciones, a partir de determinaciones estaduales, resultó en peculiaridades que motivaron el tránsito de alumnos que cruzaron la frontera en busca de una formación mejor y más rápida. En diciembre de 1938 cambio en la estructura educativa en Santa Catarina extinguió la formación de profesores complementarios; el acontecimiento que repercutió no sólo del lado catarinense de la frontera, porque interrumpió el intercambio de una década motivado por las Escuelas Complementarias de las dos ciudades, las escuelas cuyas actividades fueron productos y concurrieron a la producción de "percepciones de lo social" (CHARTIER, 1990).

Palabras clave: Escolar complementario. Profesor primario. Frontera.

\section{Introdução}

No início do século XX, formar professores para lecionar em escolas primárias isoladas ou simples (salas-classes multisseriadas) nos parâmetros das diretrizes educacionais que reformaram a escola normal e instituíram os grupos escolares (ARAUJO; FREITAS; LOPES (org.), 2008; MONARCHA, 1999; VIDAL (org.), 2006), foi um desafio para vários governantes brasileiros que pretendiam ampliar a escolarização popular nas primeiras décadas do período republicano - um dos pré-requisitos para modernizar a sociedade (BOTO, 2011; CARVALHO, 1998). 
Esse processo, permeado por nuanças estaduais, resultou, entre outras peculiaridades, na organização da escola complementar: uma modalidade formativa de dois ou três anos criada principalmente para suprir a demanda por professores nas escolas isoladas que atendiam a dispersa população das zonais rurais. Nas escolas complementares, o corpo docente de professores normalistas era o mesmo do grupo escolar ao qual estava anexa ${ }^{1}$. Segundo Souza (1998, p. 64), a escola complementar funcionou no mesmo edifício do grupo escolar e teve por objetivo “solucionar o problema da necessidade de formação rápida de professores para as escolas primárias".

No sul do Brasil, na divisa do Paraná com Santa Catarina, a formação de complementaristas adquiriu contornos singulares na região marcada pela Guerra do Contestado, que convulsionou a área nos anos 1910. No final da década de 1920 foram organizadas duas escolas complementares a poucos quilômetros de distância.

No final do conflito armado, que envolveu os dois estados, foram criados os municípios fronteiriços de Porto União (SC) e União da Vitória (PR), dividindo entre o Paraná e Santa Catarina o antigo município paranaense de Porto União da Vitória (BRASIL, 1917)². A instalação de Porto União (SC) em setembro de 1917 foi o grande marco da divisa interestadual. A partir desta data existiram duas cidades repartidas/unidas pela ferrovia São Paulo - Rio Grande que foi saudada anos antes, como possibilidade de progresso regional ${ }^{3}$.

Considerando que a mobilidade é uma das potencialidades da região de fronteira, permitindo intercâmbios e rearranjos socioculturais entre indivíduos e

\footnotetext{
${ }^{1}$ Nos anos 1920-30, de maneira geral existiam duas grandes categorias de professores no Paraná e em Santa Catarina: os normalistas e os não formados pela Escola Normal, subdivididos em várias categorias. Nesse universo de professores, os complementaristas catarinenses e paranaenses tinham preferência para nomeação após os normalistas, que estavam no topo da lista (PARANÁ, 1917, p.18-19; SANTA CATARINA, 1914, p. 22-23).

20 Acordo de Limites que definiu as divisas entre Paraná e Santa Catarina foi promovido pelo presidente do Brasil em 20 de outubro de 1916. Contudo, a assinatura do Acordo não correspondeu ao fim da Guerra do Contestado (oficialmente iniciada em 1912), pois o clima conflituoso se estendeu pelo menos até 1917, quando começou efetivamente a vigorar.

${ }^{3}$ A estrada de ferro chegou à localidade de Porto União da Vitória (PR) em 1906 e no ano de 1910 atravessou o pequeno conjunto urbano, estendendo os trilhos pelo estado de Santa Catarina até alcançar o Rio Grande do Sul, impulsionando mudanças na economia da região, notadamente as relacionadas à exploração madeireira. Entretanto, a ferrovia concorreu para desorganizar formas de vida rural na área concorrendo para a Guerra do Contestado, conflito balizado pela disputa de fronteira entre o Paraná e Santa Catarina e insuflado por crenças messiânicas (GALLO,1999; MACHADO, 2004; TONON, 2008).
} 
coletividades, o aqui e o ali se materializaram nesta região a partir de experiências pautadas por determinações de dois estados de um mesmo país.

Assim, diferentemente de uma fronteira internacional, nessa fronteira interestadual, a língua e os costumes eram os mesmos, mas a separação, materializada pelos trilhos do trem determinava especificidades. Como escreveu Campigoto (2010, p. 44), “[...] estudar os sentidos das regiões e das fronteiras é estudar as relações e conexões entre totalidades e partes, conjunto de sentido e componentes de significados".

Nessa perspectiva, a escola complementar foi instalada em cada uma das cidades a partir de determinações diversas, concorrendo tanto para traduzir as diferenças estaduais, quanto para conformar padrões socioculturais da população à nação brasileira. A Escola Complementar de Porto União (SC) foi criada em 1928 no Grupo Escolar Balduíno Cardoso e os alunos cursaram as mesmas disciplinas dos dois primeiros anos da Escola Normal catarinense. A Escola Complementar de União da Vitória (PR) foi instalada em 1929, anexa ao Grupo Escolar Professor Serapião, como curso preparatório para o ingresso na Escola Normal paranaense, mas sem explícito vínculo curricular com esta escola ${ }^{4}$.

Nesse período de (re)construção regional era grande a demanda por professores com formação adequada para ensinar nas instituições de ensino primário das duas cidades. Foram repetidas as publicações de editais para a seleção de professores provisórios ${ }^{5}$ para lecionar em escolas isoladas, em especial as rurais (p. ex. O Comércio, 25/2/1934, p. 6). Paralelamente, as várias notícias de jornais sobre eventos cívicos e outras festividades, que destacavam a participação de professores e alunos das escolas complementares, são indícios da importância dessas instituições

\footnotetext{
${ }^{4}$ Em 1920, o município de Porto União (SC) contava com uma população de 12.051 pessoas e o de União da Vitória (PR) com 10.527 moradores (SILVA, [1933] 2006, p.178). Certamente no final da década os números dos habitantes tinham crescidos, mas não foi possível localizá-los.

${ }^{5}$ Professor provisório em Santa Catarina era aquele que havia concluído o terceiro ou quarto ano do curso primário (SANTA CATARINA, 1914, p.22). No Paraná, para ser professor provisório era necessário ter mais de 18 anos e ter concluído a $4^{a}$ série do primário ou ser aprovado em exame de "leitura, escrita, rudimentos de aritmética, geografia e história do Brasil" (PARANÁ, 1917, p.19).
} 
para as duas cidades fronteiriças (O Comércio, Porto União, 08/05/1932, p. 1, \entre outros) ${ }^{6}$.

Concorrendo para forjar "percepções do social” (CHARTIER, 1990, p. 17), estas Escolas Complementares legitimaram e difundiram propostas de educação, balizada pela legislação dos dois estados, que foi vivenciada e reelaborada indistintamente por pessoas das duas localidades, muitas delas desejosas, para si ou seus filhos, rapazes e moças, de uma oportunidade de continuidade de estudos e de uma possibilidade de emprego quase imediato (não importava de qual lado da fronteira), com status social diferenciado, em área eminentemente agrícola.

\section{As Escolas Complementares nas cidades fronteiriças}

O processo de escolarização nas recém-criadas cidades de Porto União (SC) e União da Vitória (PR) conjugou a herança dos tempos da antiga localidade de Porto União da Vitória com as reordenações relativas ao ensino primário e formação de professores que pautaram as legislações educacionais de Santa Catarina e do Paraná nos anos 1910 (HÖELLER, 2009; MORENO, 2007). Essas determinações legais, com evidente inspiração na experiência educacional paulista, incluíram a normatização da formação de professores complementaristas.

Em Santa Catarina, a Reforma da Instrução Pública de 1910 possibilitou a instituição, em julho de 1911, da formação de professores por meio das escolas complementares (SANTA CATARINA, 1910; 1911). Esta alteração na legislação escolar, realizada sob a égide de Orestes Guimarães (formado pela Escola Normal de São Paulo), foi regulamentada ad referendum pelo Congresso catarinense, com a finalidade de "facilitar aos candidatos ao magistério público" a formação onde residem, uma vez que "nem todos podem permanecer na capital pelo tempo naquele curso [normal] exigido". As escolas complementares catarinenses ofertavam as disciplinas gerais dos dois primeiros anos das escolas normais (SANTA CATARINA, 1911).

\footnotetext{
${ }^{6}$ Entre o final dos anos 1920 e a década de 1930, em períodos variados, circularam em Porto União (SC), além do $O$ Comércio, os jornais A Voz do Oeste e A Nota. Em União da Vitória (PR) foi editado o jornal $O$ Município.
} 
Em Porto União (SC), depois dos longos anos das disputas do Contestado, a escola complementar foi criada no final da década de 1920, com a remodelação das escolas reunidas ${ }^{7}$, existentes na cidade desde 1918, que passaram a formar o Grupo Escolar Balduíno Cardoso no ano de 1927 (SANTA CATARINA, 1916a; 1916b; [1927]1928a). Como uma escola complementar deveria funcionar anexa a um grupo escolar, este ato viabilizou o Decreto no 2135, de 12 de março de 1928 (SANTA CATARINA, [1928]1929), que criou a Escola Complementar em Porto União (SC).

Neste mesmo ano, a afirmação do presidente de Santa Catarina, Adolpho Konder, no Congresso estadual, que "professores normalistas [em geral] recusam-se a servir em escolas isoladas rurais" (KONDER, 1928, p. 55), reforçou o incentivo às escolas complementares, que poderiam ser criadas em grupos escolares do interior do estado (menos gasto com pessoal e instalações) e formariam rapidamente profissionais habilitados nas próprias regiões em que deveriam atuar.

Em Porto União (SC), um dia após a festividade de instalação da Escola Complementar anexa ao Grupo Escolar Balduíno Cardoso, que ocorreu em 23 de maio de 1928, foi aberta inscrição de alunos havendo 38 jovens aptos, sendo: 23 moças e 15 rapazes, conforme o Livro de matrículas da seç̧ão masculina (1928, p. 1) e Livro de matrículas da seção feminina (1928, p. 1-2). Contudo, o quantitativo de alunos que frequentou a Escola Complementar parece ter sido bem menor. Quando Hermínio Milis inspecionou o estabelecimento, em 26 de outubro de 1929, estavam matriculados 11 alunos no primeiro ano e destes, 7 frequentavam às aulas: 4 moças e 3 rapazes (MILIS, 1929, p. 6v).

No estado do Paraná, a organização de escolas intermediárias era prevista nos Códigos do Ensino de 1915 e 1917, com o objetivo de preparar concluintes dos grupos escolares para o ingresso no ginásio ou na escola normal. Em 1917 o Código do Ensino facultou aos egressos das escolas intermediárias a nomeação como professores efetivos $^{8}$ (PARANÁ, 1915; 1917). Somente com a publicação do

\footnotetext{
${ }^{7}$ A escola reunida, ou combinada agregava no mesmo local, mas em salas diferentes, duas ou mais classes ou escolas, mas sem a efetiva estrutura didática e administrativa de um grupo escolar (LOPES, 2006).

${ }^{8}$ Professor efetivo no Paraná, também poderia ser aquele que havia cursado os dois primeiros anos da Escola Normal do estado ou que tinha apresentado diploma de escolas normais de outros
} 
Decreto $\mathrm{n}^{\circ}$ 887, de 8 de agosto de 1925, foram criadas as escolas complementares no estado do Paraná. As escolas complementares primárias, como foram nomeadas no Paraná, ofertavam ensino profissionalizante em quatro modalidades distintas (cursos de um ou dois anos), inclusive o normal (PARANÁ, 1925). Assim como em Santa Catarina, as escolas complementares paranaenses eram vinculadas aos grupos escolares, criadas em locais onde o governo considerasse oportuno, evidenciando a interdependência da expansão da formação docente com o objetivo do estado na expansão da escolarização primária.

O Grupo Escolar Professor Serapião da cidade de União da Vitória (PR) existiu desde 1913, inicialmente como casa escolar, com 4 salas de aula. (KLEIN, 2013). Foi remodelado em 1919, sob os auspícios do professor Trajano Sigwalt, diretor do Grupo Escolar Modelo Xavier da Silva, de Curitiba. Este educador integrou uma comissão de professores paranaenses que estudou procedimentos educacionais adotados no estado de São Paulo com o objetivo de modernizar aspectos do ensino paranaense (KLEIN, 2013).

Em $1^{\text {o }}$ de março de 1919 Sigwalt visitou a região e fez um registro que evidencia a permeabilidade da educação na fronteira interestadual; ele escreveu no Livro de termos de visitas das Escolas Reunidas [Grupo Escolar Balduino Cardoso] de Porto União:

Ao visitar as Escolas Reunidas de Porto União [estado de Santa Catarina], sob a competente direção do Snr. Prof. Antenor Cidade, seja-me permitido consignar os meus melhores votos de congratulações com os governos e infância do nosso querido Brasil, pelo incremento que vem, aos poucos, tomando, este reino da pública administração - a instrução [...] (SIGWALT, 1919, p. 4).

No seu registro, a autoridade educacional paranaense reafirmava a ideia de fronteira, assinalando a autonomia dos governos estaduais no desenvolvimento de ações relacionadas à educação, balizadas inclusive pelo orçamento disponível em cada estado, e, simultaneamente, reforçava a tese do pertencimento mútuo, de catarinenses e de paranaenses, à nação brasileira.

Nas cidades de Porto União (SC) e União da Vitória (PR) o contato entre autoridades educacionais e alunos, que muitas vezes cruzavam a fronteira, fazia com

estados (PARANÁ, 1917, p. 30-31). Em Santa Catarina os efetivos ou vitalícios eram os não normalistas aprovados em concurso ou exame (SANTA CATARINA, 1914, p. 22-23). 
que ações educativas fossem compartilhadas e também houvesse comparações entre a escolarização nas duas cidades. Caso significativo aconteceu em outubro de 1928. O inspetor escolar paranaense João Rodrigues, ao vistoriar o Grupo Escolar Professor Serapião, defendeu a criação de uma Escola Complementar Primária em União da Vitória (PR), usando como justificativa a tese que caso isso não ocorresse os egressos deste Grupo Escolar precisariam estudar na recém-criada Escola Complementar de Porto União (SC) (RODRIGUES, 1928, p. 1).

Não foi possível saber se já existiam iniciativas do governo paranaense, de autoridades e/ou de membros da comunidade de União da Vitória (PR) relacionadas à criação de uma Escola Complementar Primária na cidade, mas esta foi criada poucos meses depois da visita de João Rodrigues, pelo Decreto $\mathrm{n}^{\circ} 33$ de 4 de janeiro de 1929 (PARANÁ, 1929). Desta forma, no mesmo conjunto urbano passaram a existir duas escolas complementares: uma paranaense e outra catarinense, o que suscitou comparações, que por vezes sinalizavam rivalidade, como a expressa nas palavras de Rodrigues ainda antes da efetiva criação da Escola Complementar em Porto União (PR).

Como em outras partes do Brasil, professoras e professores das duas Escolas Complementares também atuavam nos Grupos Escolares aos quais as Escolas estavam anexas, em nada modificando os quadros dos Grupos Escolares ou os vencimentos de professores e diretores. Os governos do Paraná e de Santa Catarina determinavam o currículo, método de ensino, prescrições sobre o funcionamento escolar e realizavam a fiscalização das Escolas. Os municípios zelavam pela organização e manutenção, inclusive do espaço físico, das Escolas Complementares (STENTZLER, 2015, p. 100-101).

Em 26 de abril de 1930 o inspetor escolar Simeão Pedrosa, em visita à Escola Complementar Primária de União da Vitória (PR), registrou a presença de 19 alunos no $1^{\circ}$ ano (23 matriculados) e 10 no $2^{\circ}$ ano (14 matriculados). Sem fazer distinção entre o número de moças e de rapazes presentes, afirmou que esses, "arguidos em aritmética, português, geografia e ciências físicas, revelaram algum adiantamento" (PEDROSA, 1930, p. 1). 
No mesmo ano, do outro lado dos trilhos, a Escola Complementar de Porto União (SC) foi inspecionada por Hermínio da Silva Milis. Seu registro apontou a existência de problemas de ordem material e pedagógica na instituição. Segundo Milis (1930, p. 7v), a prática de várias disciplinas teria sido "bastante prejudicada" devido ao "inferior aparelhamento [escolar]": complementaristas estudavam na sala do $3^{\circ}$ e $4^{\circ}$ anos do Grupo Escolar e utilizavam o mesmo material didático dos alunos dessas séries.

O mesmo relatório de 1930 sinalizou a falta de compromisso da professora da Escola Complementar, da qual o inspetor cobrava o "cumprimento de seus deveres, com mais assiduidade" a fim de que a escola não "sofra maiores prejuízos uma vez que, entre nós, existe outra, congênere [em União da Vitória (PR)]”. Havia 11 alunos matriculados na Escola Complementar de Porto União (SC), todos no $1^{\circ}$ ano: "4 na seção masculina e 7 na feminina” (MILIS, 1930, p. 7, v-8).

Dois anos depois, em 1932, foram 33 os alunos matriculados na Escola Complementar Primária de União da Vitória (PR), enquanto no final de 1933 eram somente 9 os matriculados na Escola Complementar de Porto União (SC) (FALARZ, 1932, p. 3v; WAGENFÜHR, 1934, p. 22v). Em 1933 a Escola Complementar do lado catarinense da fronteira diplomou apenas 2 moças e na Escola Complementar Primária de União da Vitória (PR) foram 15 os jovens que concluíram o curso: 7 moças e 8 rapazes (REGISTRO, 1931-1938, p. 9v-10; REGISTRO, 1933-1943, p. 1-4). Fica evidente que na região abalada por anos de guerra e, concomitantes, problemas econômicos, o magistério ainda atraia muitos rapazes, ao contrário de muitas outras localidades brasileiras.

Enquanto a Escola Complementar de Porto União (SC) ofertava um curso de três anos (com disciplinas do $1^{\circ}$ e $2^{\circ}$ anos da Escola Normal catarinense) a congênere, do lado do Paraná ofertava um curso "profissional" de dois anos que também habilitava os egressos para a matrícula no $1^{\circ}$ ano da Escola Normal mesmo não reproduzindo em suas aulas conteúdos desta instituição, como ocorria em Santa Catarina. O tempo menor do curso deve ter motivado muitos jovens da cidade vizinha a atravessar a fronteira para estudar em União da Vitória (PR). 
Além disso, na Escola Complementar Primária de União da Vitória (PR) atuava a professora normalista Amasilia Araújo, que lecionava na região desde 1904 (tempos da antiga cidade de Porto União da Vitória) e foi descrita, em 1917, pelo inspetor escolar João Túlio Marcondes de França, como uma "exímia educadora [que] prima pelo gosto ao desempenho da sua nobilitante função" (FRANÇA, 1917, p. 3). Ensinando há tantos anos, a "exímia educadora" deveria conhecer muitos dos pais e avós de seus alunos complementaristas (vindos de ambos os lados da fronteira), bem como o cotidiano e costumes da região, o que também pode ter motivado a permanência de jovens, por vontade própria ou imposição familiar, na Escola Complementar Primária do lado paranaense ${ }^{9}$.

Mas, enquanto os comentários de visitantes eventuais ou de inspetores escolares eram, na grande maioria, elogiosos ao ensino ministrado na Escola Complementar Primária de União da Vitória (PR), o mesmo não acontecia do outro lado da fronteira. Isso talvez fosse resultado das dificuldades da Escola Complementar de Porto União (SC) para se adequar ao perfil exigido das escolas complementares catarinenses, ou seja, uma instituição que, efetivamente, também preparava para o ingresso na escola normal, como evidenciava seu currículo.

Nesse sentido, não eram poucos os desafios da Escola Complementar de Porto União (SC). Um dos principais foi superar a carência de livros adequados para complementaristas. Segundo relatou o inspetor Elpídio Barbosa em 1933, essa carência prejudicava ações didático-pedagógicas para uma escolarização eficaz, pois concorria para a simples repetição dos conteúdos já trabalhados no $4^{\circ}$ ano do Grupo Escolar. Em tempos de difusão de propostas escolanovistas ${ }^{10}$, o inspetor recomendava aulas mais práticas e almejava a mudança escolar com a participação efetiva de seus professores (BARBOSA, 1933).

Mas, para a população em geral, esses problemas eram suplantados por notícias que valorizavam a Escola Complementar de Porto União (SC). Em maio de 1932, por exemplo, artigo de primeira página do O Comércio, parabenizou Alice de

\footnotetext{
${ }^{9}$ Em 1933 eram duas as professoras normalistas que ensinavam na Escola Complementar Primária de União da Vitória (PR): Amasilia Araújo e Isaura Torres Cruz (SILVA, [1933] 2006, p. 236).

${ }^{10}$ Sobre as propostas educacionais desse período, veja: Miguel; Vidal; Araújo (orgs.) (2011).
} 
Paula Dias, formada na primeira turma deste estabelecimento escolar, que havia sido nomeada professora da Escola Isolada de Pinheiros, no distrito de Vallões — Porto União (SC). O autor do texto (não assinado) cumprimentou a direção da Escola pelo sucesso da aluna (O Comércio, Porto União, 1/5/1932, p. 1).

Festividades como as do Dia da Escola, instituído em Santa Catarina pelo decreto $\mathrm{n}^{\circ}$ 2016, de 19 de janeiro de 1927, também podem ter concorrido para a popularização da Escola Complementar de Porto União (SC). Comemorado todo dia 15 de outubro, “[...] nos institutos de ensino primário do estado, em qualquer grau, públicos ou particulares”, no Dia da Escola as aulas ocorriam regularmente, mas os pais e familiares dos alunos poderiam observar "[...] os diversos desdobramentos e aspectos dos trabalhos escolares" A programação de "passeios campestres" previstos para o dia seguinte, com professores, alunos, familiares e amigos, concluía as atividades dessa data comemorativa (SANTA CATARINA, 1928b, p. 142-143).

Desta foram, um misto de atividade escolar e social, o Dia da Escola dava visibilidade ao trabalho realizado nas instituições de ensino e congregava, inclusive fora do espaço escolar, escola e sociedade. As festividades de 1931 realizadas pelas escolas de Porto União (SC) foram uma das quais os complementaristas da cidade tomaram parte (SILVEIRA, 1931, p. 5).

Mas, como alertam Bencostta e Pereira (2006), muitos dos festejos escolares se inserem numa “dimensão sócio-histórica mais ampla”. Nesse sentido, algumas das comemorações que aconteciam nas Escolas Complementares de Porto União (SC) e de União da Vitória (PR) eram momentos de integração das duas cidades. Como escreveu Teive (2008, p. 34) as escolas complementares foram "instâncias civilizadoras e inculcadoras de novos valores e normas de comportamento".

Como noticiou o jornal O Comércio de outubro de 1933, as comemorações do Dia da Escola em Porto União (SC) contaram com a participação do Grupo Escolar e Escola Complementar Primária da cidade vizinha:

[esta] cidade e a de União da Vitória [organizaram] conjuntamente, na terça-feira da semana finda, grande piquenique no arrabalde [do distrito de] Tocos. A essa festa, estiveram presentes os diretores de ambos aqueles estabelecimentos escolares [Grupos Escolares e Escolas Complementares anexas] e os respectivos docentes (O Comércio, Porto União, 22/10/1933, p. 6). 
E esse intercâmbio, pautado inclusive pelas duas instituições complementaristas, pode ter sido reforçado pela possibilidade de pessoas nascidas ou formadas na cidade de Santa Catarina atuarem do lado paranaense e vice-versa. Assim, em 1934, Noêmia Schultz, uma "inteligente professora" complementarista, nascida no Paraná e formada em 1932 na Escola Complementar de Porto União (SC), foi nomeada para a recém-criada Escola Estadual na colônia Maratá, em Porto União (SC) (O Comércio, Porto União, 7/10/1934, p. 6).

Mas, apesar de notícias como essas, que propagandeavam a Escola de Porto União (SC), a discrepância do número de formandos em favor da Escola Complementar Primária de União da Vitória (PR) preocupou as autoridades catarinenses pelo menos nos primeiros anos da década de 1930. Em 1934, segundo os relatórios oficiais, a situação aparentemente começou a mudar. Neste ano o inspetor escolar Germano Wagenführ escreveu: "notei em todas [as professoras] muito boa vontade, esforço, zelo e dedicação como raras vezes encontrei em todas as minhas inspeções; aqui todas procuram cumprir da melhor maneira, a sua espinhosa missão [...]" (WAGENFÜHR, 1934, p. 22v).

Essas considerações coincidiram com os primeiros meses de atuação na Escola Complementar de Porto União (SC) de três normalistas nascidas em Santa Catarina e formadas, em 1932, na primeira turma da Escola Normal Santos Anjos desta cidade. Uma escola confessional inaugurada em 1929 (KLEIN, 2016). Eram elas: Edith Mello, Alba Assis e Diva Eugenia de Oliveira, jovens com formação especializada, que em alguma medida compartilhavam hábitos, demandas e carências dos moradores locais.

Retomando as considerações de Wagenführ, de 1934, este afirmou que o novo diretor da Escola Complementar, professor Celso Rila, promoveu um ambiente de harmonia, ordem, assiduidade, disciplina e aproveitamento geral com "[uma] competente e acertada direção e tudo isso alcançou com um professorado que está no primeiro ano de sua carreira" (WAGENFÜHR, 1934, p. 21v-22v, grifo nosso). Segundo o inspetor, as mudanças foram resultado de "exigências locais, principalmente para poder rivalizar com os demais estabelecimentos de ensino destas duas cidades gêmeas e rivais” (WAGENFÜHR, 1935, p. 23). 
No entanto, talvez tenha sido a alteração na estrutura curricular das escolas complementares catarinenses a motivação decisiva para atrair e manter os alunos na Escola Complementar de Porto União (SC). Em 5 de janeiro de 1935 o Decreto n ${ }^{\circ}$ 713 do estado de Santa Catarina transformou as Escolas Complementares em Escolas Normais Primárias. Mantendo a finalidade de "formar professores para as zonas rurais” (SANTA CATARINA, [1935]1936, p. 162), a Escola Normal Primária continuava ofertando as disciplinas gerais dos dois primeiros anos das escolas normais e também a disciplina Noções de Pedagogia e Psicologia que, de forma conjugada, trabalhava conteúdos específicos de duas disciplinas dos cursos normais.

Em Porto União (SC) o número de matriculados na Escola Complementar que já tinha saltado de 9 alunos em 1933 para 21 matriculados em 1934, foi de 35 inscritos em 1935 (WAGENFÜHR, 1935, p. 27v). Nos anos seguintes, a mudança criou uma nova mobilidade de estudantes pela fronteira interestadual, agora em sentido inverso. Egressos da Escola Complementar Primária de União da Vitória (PR) que desejassem complementar, gratuitamente, seus estudos, cursavam mais um ano na Escola Normal Primária de Porto União (SC), o que oferecia uma oportunidade de atuação até em grupos escolares, na falta de professores formados por escolas normais. Esse parece ter sido o caso de Cícero Otomar de França e de Guilhermina Liegel, ambos diplomados em 1934 na Escola Complementar do lado paranaense e formados, em 1935, na Escola Normal Primária do outro lado da fronteira (REGISTRO 1931-1938; REGISTRO, 1933-1943).

Mas esse tipo de movimentação teve existência curta. Em 1938 o governo catarinense remodelou/extinguiu a Escola Normal Primária, pelo o Decreto $n^{\circ} 244$, de 8 de dezembro, e criou o Curso Complementar anexo ao Grupo Escolar, por considerar um curso de dois anos, que correspondia as duas primeiras séries ginasiais, o mais adequado para existir junto aos estabelecimentos de ensino primário. Essa mudança, entre outras alterações curriculares, excluiu a disciplina Noções de Pedagogia e Psicologia e inseriu aulas de Orfeão e de Educação Física na nova modalidade de formação escolar (SANTA CATARINA, [1938] 1939, p. 417-420). 
O novo conjunto formativo sinalizou um novo significado pedagógico para a escolarização primária, que refletiu as mudanças de diretrizes educacionais federais implementadas pela gestão Getúlio Vargas e gestadas pelo menos desde a década de 1920 (CARVALHO, 1998). Mudanças que, no que diz respeito à escola complementar paranaense, fizeram sua existência perdurar por mais alguns anos, com finalidade cada vez mais diversa da original.

A partir do final da década de 1930, a formação de professores passou a se tornar, gradativamente, prioridade dos Institutos de Educação, em Santa Catarina, e das Escolas Normais, no Paraná.

Entre dezembro de 1931 e dezembro de 1938 foram 32 moças e 18 rapazes os diplomados pela Escola Complementar e pela Escola Normal Primária de Porto União (SC), conforme o registro de diplomas desses estabelecimentos de ensino (REGISTRO, 1931-1938). Do outro lado da fronteira, entre 1933 e 1938 (não foram localizados dados anteriores a 1933) foram 17 moças e 20 rapazes formados pela Escola Complementar de União da Vitória (PR) (REGISTRO, 1933-1943).

\section{Considerações finais}

Os complementaristas, formados prioritariamente para atuar na zona rural, fizeram parte do cotidiano das cidades de Porto União (SC) e União da Vitória (PR) entre 1928 e 1938, inclusive após a criação catarinense da Escola Normal Primária, em 1935, pois normalistas primários, mesmo com status diferenciado, eram considerados complementaristas. Assim, as instituições de ambas as cidades existiram ao mesmo tempo e, por vezes, suplementando a formação de jovens professores na região que havia sido disputada por Paraná e Santa Catarina.

Não há como quantificar a opção dos jovens por uma ou outra dessas Escolas, a hipótese é que grande parte dos alunos era formada por egressos dos respectivos Grupos Escolares. Mas vários desses jovens, ou seus pais, de Porto União (SC) e de União da Vitória (PR), fizeram comparações entre essas instituições e, em muitos casos, optaram pela da cidade vizinha, pelo menos para completar os 
estudos. A divisa territorial materializada apenas pela linha do trem facilitava a mobilidade e a interação.

A boa fama de docentes e diretores e sua interação com as comunidades locais podem ter fundamentado a escolha por uma das Escolas de complementaristas que, apesar das dificuldades cotidianas, por vezes explicitadas na falta de material adequado para as aulas, formaram professores que atuaram dos dois lados da fronteira na região do Contestado - uma região que carecia de professores para a área rural e, aparentemente, não ofertava muitas possibilidades de emprego, inclusive para homens jovens, pelo menos nas primeiras décadas depois do conflito.

Quando em dezembro de 1938 a Escola Normal Primária de Porto União (SC) foi extinta, o jornal O Comércio (único periódico da região naquele ano) não emitiu opinião sobre a mudança que aconteceu na estrutura escolar em Santa Catarina. Era tempo da ditadura do Estado Novo, com notícias censuradas, o que pode explicar o silêncio da impressa sobre o acontecimento, que deve ter repercutido entre os moradores das duas cidades ${ }^{11}$, pois interrompeu o intercâmbio de uma década entre escolas formadoras de professores complementaristas que atuaram tanto no município de Porto União (SC), quanto no de União da Vitória (PR).

\section{Referências}

ARAUJO, J. C. S.; FREITAS, A. G. B. de; LOPES, A. de P. C (orgs.) As escolas normais no Brasil. Campinas: Alínea, 2008.

BARBOSA, E. Inspeção escolar. Livro de registro de visitas de inspetores. Educação Básica Prof. Balduíno Cardoso. Porto União (SC), 1933.

BENCOSTTA, M. L. A.; PEREIRA, A. P. P. História, cultura, sociabilidades: representações e imagens de festas escolares (Curitiba, 1903-1971). Congresso LusoBrasileiro de História da Educação, V, Uberlândia. Anais... Uberlândia: Edufu, 2006. Disponível em: <https://docplayer.com.br/1538168-Historia-cultura-e-sociabilidadesrepresentacoes-e-imagens-das-festas-escolares-curitiba-1903-1971-1-resumo.html>. Acesso: 14 jan. 2017.

${ }^{11}$ Dois anos depois do fim da Escola Normal Primária catarinense, o município de Porto União (SC) tinha 20.823 habitantes e o de União da Vitória (PR) contava com 29.636 moradores (IBGE, 1940ab). 
BRASIL, Decreto $\mathrm{n}^{\circ} 3304$ de 3 de agosto de 1917. Disponível em $<$ http://www.lexml.gov.br/urn/urn:lex:br:federal:decreto:1917-08-03;3304>. Acesso em: 19 out. 2016.

BOTO, C. A racionalidade escolar como processo civilizador: moral que captura alma. In: CARVALHO, M. M. C. de; PINTASSILGO, J. (orgs.). Modelos culturais, saberes pedagógicos, instituições educacionais. São Paulo: Edusp, 2011. p.47-80.

CAMPIGOTO, A, Linguagem, fronteira, região e história. In: SALES, J. R.; FREITAG, L.; STANZICK FILHO, M. (Orgs.). Região: Espaço, linguagem e poder. São Paulo: Alameda, 2010. p. 53-70.

CARVALHO, M. M. C. de. Molde nacional e forma cívica. Bragança Paulista: Edusf, 1998.

CHARTIER, R. Introdução. A bistória cultural. Rio de Janeiro: Editora Bertrand, 1990. p. $14-28$.

FALARZ, S. Inspeção escolar. Termo de visitas e inspeções na Escola Complementar Primária anexa ao Grupo Escolar Professor Serapião. União da Vitória (PR), 1932.

FRANÇA, J. T. M, Inspeção e exame. Termo de visitas de inspetores e dos exames da Escola Feminina do Grupo Escolar Professor Serapião do Nascimento. União da Vitória (PR), 1917.

GALLO, I. C. A. O Contestado. Campinas: Editora da Unicamp, 1999.

HÖELLER, S. A. O. Escolarização da infância catarinense: a normatização do ensino primário (1900-1935). Dissertação (Mestrado em Educação) — Programa de Pós-Graduação em Educação. Universidade Federal do Paraná, 2009.

IBGE. Censo demográfico: Estado do Paraná. União da Vitória. 1940a. Disponível em: <https://ia802504.us.archive.org/3/items/censo1940vol18pr/censo1940vol18pr.pdf>.

Acesso em: 31 jan. 2019.

IBGE. Censo demográfico: Estado de Santa Catarina. Porto União. 1940b. Disponível em: <https://ia902506.us.archive.org/25/items/censo1940vol19sc/censo1940vol19sc.pdf>.

Acesso em: 31 jan 2019.

KLEIN, R. B. Grupo Escolar Professor Serapião: 100 anos de história. Palmas: Kaygangue, 2013.

KONDER, A, Mensagem apresentada à Assembleia Legislativa do Estado de Santa Catarina. 29 de julho de 1928. Disponível em: <http://brazil.crl.edu/bsd/bsd/u983/000001.html>. Acesso: 20 nov. 2016.

LIVRO de matrícula para a seç̧ão feminina da Escola Complementar annexa ao Grupo Escolar Prof. Balduino Cardoso. Porto União (SC), 1928-1964a.

LIVRO de matrícula para a seção masculina da Escola Complementar annexa ao Grupo Escolar Prof. Balduíno Cardoso. Porto União (SC), 1928-1964b.

LOPES, A. de P. C. Das escolas reunidas ao grupo escolar. In: VIDAL, D.G. (org.) Grupos escolares. Campinas: Mercado das Letras, 2006. p. 81-107. 
MACHADO, P. P. Lideranças do Contestado. Campinas: Editora da Unicamp, 2004.

MIGUEL, M. E. B.; VIDAL, D. G.; ARAUJO, J. C. S. (orgs.). Reformas educacionais: as manifestações da Escola Nova no Brasil (1920-1946). Campinas; Uberlândia: Autores Associados; Edufu, 2011.

MILIS, H. A. da S. Inspeção Escolar. Livro de termos de visitas das Escolas Reunidas [Grupo Escolar Balduíno Cardoso] de Porto União - 1918-1969. Porto União (SC), 1929-1930.

MONARCHA, C. Escola Normal da Praça. Campinas: Editora da Unicamp, 1999.

MORENO, J. C. Intelectuais na década de 1920: César Prieto Martinez e Lysimaco Ferreira da Costa à frente da instrução pública no Paraná. In: VIEIRA, C. E. (org.) Intelectuais, educação e modernidade no Paraná (1886-1964). Curitiba: Editora UFPR, 2007. p. 41-64.

O COMÉRCIO, Porto União (SC), 1930-1939.

PARANÁ, Decreto no 17 de 9 de janeiro de 1917. Leis, decretos e regulamentos. Curytiba: Typ. d'A Republica, 1917.

PARANÁ, Decreto no 33 de 4 de janeiro de 1929. Diario Official Estado. Curytiba, 21 de janeiro de 1929.

PARANÁ, Decreto no 710 de 18 de outubro de 1915. Leis, decretos e regulamentos. Curytiba: Typ. da República, 1915.

PARANÁ, Decreto no 887 de 8 de agosto de 1925. Diario Official Estado. Curytiba, 14 de agosto de 1925.

PEDROSA, S. Inspeção escolar. Termo de visitas e inspeções escolares na Escola Complementar Primária anexa ao Grupo Escolar Professor Serapião. União da Vitória (PR), 1930.

REGISTRO de diplomas da Escola Complementar anexa ao Grupo Escolar Balduino Cardoso. Porto União (SC), 1931-1938.

REGISTRO de diplomas da Escola Complementar Primária anexa ao Grupo Escolar Professor Serapião. União da Vitória (PR), 1933-1943.

RODRIGUES, J. Inspeção escolar. Termo de visitas de inspectores e dos escolares da Escola Complementar Primária anexa ao Grupo Escolar Professor Serapião. União da Vitória (PR), 1928.

SANTA CATARINA, Decreto no 1204 de 19 de fevereiro de 1919. Colleç̧ão de leis e decretos. Florianópolis: Officinas Imprensa Official, 1919.

SANTA CATARINA, Decreto no 2017 de 19 de janeiro de 1927. Colleção de leis, decretos e resoluçoes. Florianópolis: Typ. Livraria Moderna, 1928a.

SANTA CATARINA, Decreto $\mathrm{n}^{\circ} 2135$ de 12 de março de 1928. Collecção de leis e decretos e resoluções. Florianópolis: Off. Graph. Escola de A. Artífice,1929.

SANTA CATARINA, Decreto n ${ }^{\circ} 244$ de 8 de dezembro de 1938. Coleção de decretos-leis. Florianópolis: Imprensa oficial do Estado, 1939. 
SANTA CATARINA, Decreto no 604 de 11 de julho de 1911. Collecção de leis e decretos. Florianópolis: Gab. Typ. O Dia, 1911.

SANTA CATARINA, Decreto no 713 em 5 de janeiro de 1935. Coleção de decretos, resoluções e portarias. Florianópolis: Livraria Central de Alberto Entres, 1936.

SANTA CATARINA, Decreto $\mathrm{n}^{\circ} 929$ de 5 de abril de 1916. Colleç̧ão de leis e decretos. Florianópolis: Officinas d'O Dia, 1916b.

SANTA CATARINA, Decreto nº2016 de 19 de janeiro de 1927. Colleção de Leis, Decretos e Resoluções. Florianópolis: Typ. Livraria Moderna, 1928b.

SANTA CATARINA, Lei no 1044 de 14 de setembro de 1915. Collecção de leis e decretos. Florianópolis: Officinas d'O Dia, 1916a.

SANTA CATARINA, Lei no 794 de 02 de maio de 1914. Colleçãa de leis e decretos. Florianópolis: 1914.

SANTA CATARINA, Lei $\mathrm{n}^{\circ} 846$ de 11 de outubro de 1910. Collecção de leis e decretos. Joinville: Typ. Boehm, 1910.

SILVA, C. da. Apontamentos históricos de União da Vitória (1768-1933). [1933]. Reimpressão. Curitiba: Imprensa Oficial, 2006.

SILVEIRA, M. P. Dia da Escola. Livro de termos de visitas das Escolas Reunidas [Grupo Escolar Balduino Cardoso] de Porto União - 1918-1969. Porto União (SC), 1931.

SIGWALT, T. Registro de visita. Livro de termos de visitas das Escolas Reunidas [Grupo Escolar Balduíno Cardoso] de Porto União - 1918-1969. Porto União (SC), 1919.

SOUZA, R. F. Templos de civilização. São Paulo: Editora Unesp, 1998.

STENTZLER, M. M. Entre questões lindeiras e a superação de fronteiras: a escola complementar em Porto União (SC) e União da Vitória (PR) 1928-1938. Tese (Doutorado em Educação) - Programa de Pós-Graduação em Educação da Universidade Federal do Paraná. Curitiba, 2015.

TEIVE, G. M. G. Uma vez normalista, sempre normalista. Florianópolis: Insular, 2008.

TONON, E. As cidades de Porto União e União da Vitória no contexto do movimento do Contestado. In: MARTINS, I.; GOHL, J.; GASPARI, L. (orgs). Fragmentos de memória, trechos do Iguaçu: olhares e perspectivas de história local. União da Vitória, FAFIUV, 2008.

VIDAL, D. G. (org.). Grupos Escolares: cultura escolar primária e escolarização da infância no Brasil (1893-1971). Campinas: Mercado das Letras, 2006.

WAGENFÜHR, G. Inspeção escolar. Livro de registro de visitas de inspectores. Escola de Educação Básica Prof. Balduíno Cardoso. Porto União (SC), 1934-1939.

RECEBIDO: 10/03/2019

APROVADO: 25/05/2019
RECEIVED: 03/10/2019

APPROVED: 05/25/2019
RECIBIDO: 10/03/2019

APROBADO: 25/05/2019 